\title{
Morphological changes in Golgi apparatus induced by brefeldin A treatment in tobacco protoplasts
}

\author{
Takako S. Kaneko ${ }^{1}$, Rei Watanabe ${ }^{1}$, Mamiko Sato $^{2}$, Masako Osumi $^{1}$ and \\ Akira Takatsuki ${ }^{3}$
}

Recieved September 13,1994

\begin{abstract}
${ }^{1}$ Department of Chemical and Biological Sciences, Faculty of Science, Japan Women's University, ${ }^{2}$ Laboratory of Electron Microscopy, Japan Women's University, Mejiro-dai, Bunkyo-ku, Tokyo 112 and ${ }^{3}$ Animal and Cellular Systems Laboratory, The Institute of Physical and Chemical Research(RIKEN), Hirosawa, Wako-shi, Saitama 351-01, Japan
\end{abstract}

Key Words: Nicotiana tabacum L. var. Xanthi; tobacco cells; tobacco protoplasts; Golgi apparatus; brefeldin A.

\begin{abstract}
We investigated the effect of brefeldin $\mathrm{A}(\mathrm{BFA})$ on the Golgi apparatus in cultured tobacco protoplasts. Within $3 \mathrm{hr}$ of treatment with brefeldin $\mathrm{A}(10 \mu \mathrm{g} / \mathrm{ml})$, the diameter of the Golgi cisternae became about four times greater than the control. The expanded cisternae were loosely organized, their tips were sprinkled with ribosomes and the distance between the cisternae increased. No other significant morphological changes were detected, except the appearance of many vacuoles. From these observations it was concluded that BFA causes morphological changes in Golgi apparatus.
\end{abstract}

\section{Introduction}

Brefeldin $\mathrm{A}(\mathrm{BFA})$ is a hydrophobic macrolide antibiotic produced by several fungi (Hayashi et al., 1974). BFA specifically inhibits the export of newly synthesized proteins at an early step in protein transport in mammalian and yeast cells (Takatuki and Tamura, 1985; Misumi et al., 1986; Oda et al., 1987; Fujiwara et al., 1988; Kato et al., 1989; Arioka et al., 1991;Graham et al., 1993). The drug has been shown to induce a disorganization of the Golgi structure and the gradual redistribution of Golgi proteins to the endoplasmic reticulum(ER) (Fujiwara et al., 1988; Doms et al., 1989; Lippincott-Schwartz et al., 1989; 1990). In some plant cells, disruption of Golgi apparatus was induced by BFA through vesiculation of the cisternae (Satiat-Jeunemaitre and Haws, 1992a; 1992b; Schindler et al., 1994), while in other plant cells BFA caused morphological changes, but disintegration of Golgi complexes was not observed (Driouich et al., 1993; Kimura et al., 1993).

In tobacco cells, two types of acid phosphatase (EC 3.1.3.2, APase) are secreted by tobacco protoplasts during the cell wall regeneration procedure and only one is sensitive to the action of BFA on its secretion (to be published elsewhere). This work led us to 
investigate the effects of BFA on the ultrastructure of the Golgi complexes to determine the BFA action on the secretion of APase of tobacco cells. This paper reports morphological changes of Golgi complexes of tobacco cells resulting from treatment with BFA.

\section{Materials and Methods}

\section{Plant material and culture method}

Cell line XD-6, derived from Nicotiana tabaccum L. var. Xanthi was used. The initial inoculum was $c a 2.0 \mathrm{~g}$ fr.wt.per $40 \mathrm{ml}$ of medium. Cells were subcultured in $40 \mathrm{ml}$ of modified Murashige and Skoog's medium (Yamaoka et al., 1969) in a $100 \mathrm{ml}$ flask, with subculture every 10 days, at $25^{\circ} \mathrm{C}$ under dim light during the day. The flasks were agitated on a reciprocal shaker $(5 \mathrm{~cm}$ amplitude) operated at $110 \mathrm{rpm}$.

\section{Isolation of protoplasts}

Cells were harvested 6 to 7 days after subculture by centrifugation at $173 \times g$ while in the logarithmic phase of growth. They were then resuspended in a solution that contained $2 \%(\mathrm{w} / \mathrm{v}$ ) cellulase Onozuka R-10 (Yakult Honsha Co., Ltd., Tokyo, Japan), $0.05 \%$ (w/v) pectolyase Y-23 (Seishin Pharmaceutical Co., Ltd., Tokyo, Japan), and $0.1 \%$ (w/v) carboxymethyl cellulose dissolved in $0.48 \mathrm{M}$ mannitol, $\mathrm{pH} 5.2$. After incubation for $40 \mathrm{~min}$ at $30^{\circ} \mathrm{C}$, protoplasts were separated from aggregates of undigested cells by successive passages through $1.70 \mathrm{~mm}$ and $510 \mu \mathrm{m}$ mesh stainless steel and a $60 \mu \mathrm{m}$ mesh nylon sieve. The population of protoplasts was then purified by sedimentation through $13.7 \%$ sucrose at $173 \times g$ for $1 \mathrm{~min}$. and referred to as 'fresh protoplast'.

\section{Culture of protoplasts for regeneration of cell walls.}

Protoplasts were suspended in cell wall-regeneration medium [protoplast medium, originally described by Nagata and Takebe (1970) and modified] with or without $10 \mu \mathrm{g} / \mathrm{ml} \mathrm{BFA}$ to a final density of about $10^{5}$ protoplasts per ml. BFA was purified from cultures of a fungus as reported previously (Tamura et al., 1968). The suspension was distributed into 6 - $\mathrm{cm}$ petri dishes, $5.7 \mathrm{ml}$ in each, and incubated at $25^{\circ} \mathrm{C}$.

\section{Electron microscopy}

Tobacco protoplasts cultured in a petri dish were removed at 1-hr intervals during the incubation and placed in a tube. After separation from the protoplast medium by gentle centrifugation, the protoplasts were washed in $0.48 \mathrm{M}$ mannitol. The sedimented tobacco protoplasts were immobilized in beads of calcium alginate by the method by Draget et al. (1988). The alginate beads were transferred to a solution of $4 \%(\mathrm{v} / \mathrm{v})$ glutaraldehyde in $0.1 \mathrm{M} 2$-( $\mathrm{N}$-morpholino) ethanesulfonic acid- $\mathrm{NaOH}$ buffer $(\mathrm{pH} 7.2$ ) that contained $0.4 \mathrm{M}$ glucose(MG buffer) and left standing for $2 \mathrm{hr}$ at $4^{\circ} \mathrm{C}$.

The alginate beads were then washed three times with $\mathrm{MG}$ buffer at $4^{\circ} \mathrm{C}$ and the samples were post-fixed with $2 \% \mathrm{OsO}_{4}$ in $\mathrm{MG}$ buffer for $90 \mathrm{~min}$. The beads were washed and dehydrated in increasing concentrations of ethanol and then in acetone. The dehydrated samples were embedded in epoxy resin (Quetol 651), cut into thin sections, stained with 4 
$\%$ uranyl acetate and $4 \%$ lead citrate, and then examined with a JEOL 1200EXS electron microscope.

\section{Results and Discussion}

\section{Ultrastructural changes in the BFA treated protoplasts}

We recently demonstrated that the cell wall regeneration of the tobacco protoplasts was completely inhibited in the presence of $10 \mu \mathrm{g} / \mathrm{ml} \mathrm{BFA}$ and that the protoplasts were further damaged morphologically in the presence of an increasing concentration of the drug $(50 \mu \mathrm{g} / \mathrm{ml})$ (Kaneko and Terasawa 1993). BFA $(10 \mu \mathrm{g} / \mathrm{ml})$ inhibited the secretion of one type of the isoform of the APase but did not inhibit the other type after $3 \mathrm{hr}$ treatment (to be published elsewhere). In this paper we used the BFA concentration of $10 \mu \mathrm{g} / \mathrm{ml}$ to investigate the effect of the drug on the Golgi apparatus of tobacco protoplasts.

\section{Control protoplast}

Protoplasts were immobilized in bead of calcium alginate as described in 'Materials and Methods'. Cell membrane was observed in the boundary between the protoplast and the calcium alginate. In untreated fresh protoplasts the cisternae of the Golgi apparatus were parallel (Fig. 1a, $\mathrm{G}_{1}, \mathrm{G}_{2}$ ). Golgi stacks consisted of 4 to 6 flattened cisternae which were also parallel with each other (Fig. 1a). A total thickness of these parallely-lined cisternae was about $0.2 \mu \mathrm{m}$ and these cisternae were about $0.7 \mu \mathrm{m}$ long as shown in Fig. 1b (higher magnification of $\mathrm{G}_{1}$ and $\mathrm{G}_{2}$ shown in Fig. 1a). The Golgi stack in the untreated control protoplast incubated in protoplast medium for $3 \mathrm{hr}$ was recognized to be consisted of 5 flattend cisternae which were also parallel with each other. (Fig. 2).

\section{BFA-treated protoplasts}

After treatment with $10 \mu \mathrm{g} / \mathrm{ml} \mathrm{BFA}$ for only $1 \mathrm{hr}$, changes in the structure of Golgi stacks were already observed: the cisternae were not in parallel with each other but were spread apart near the edges (Figs. 3a, b and c). The cisternae were, however, scarcely observed to spread apart within $10 \mathrm{~min}$ of exposure to the drug (data not shown). The edges of the cisternae were disordered and part of the cisternae was expanded (Fig. 3c, $\nleftarrow$ ); a few ribosomes were attached to the surface of these extended cisternae (Figs. $3 \mathrm{~b}$ and $\mathrm{c}$, $<)$.

After $2 \mathrm{hr}$ of incubation of the protoplasts with BFA, part of the cisternae were greatly extended (Fig. $4 \mathrm{a} \leftarrow$ ). The number of ribosomes attached to the surface of the cisternae was increased (Fig. 4b, <).

After treatment with $10 \mu \mathrm{g} / \mathrm{ml} \mathrm{BFA}$ for $3 \mathrm{hr}$, the distorted Golgi cisternae became wider than those in control protoplasts (compare Fig. 5a and Figs. 1b and 2). As shown in Fig. 5b, the expanded cisternae were loosely organized, their tips were sprinkled with ribosomes (Fig. $5 \mathrm{~b}<$ ), and the distance between cisternae was increased. The thickness of the cisternae of the Golgi stack was about $0.3 \mu \mathrm{m}$ and the length of them was about $3 \mu \mathrm{m}$. The diameter of BFA treated Golgi cisternae became about four times greater than the control (compare Fig. $5 \mathrm{~b}$ and Figs. $1 \mathrm{~b}$ and 2).

In BFA-treated $(10 \mu \mathrm{g} / \mathrm{ml})$ rice cells the Golgi cisternae became more than double the width of those in control (Kimura et al., 1993). Besides these changes, many small vacuoles became apparent after treatment with $10 \mu \mathrm{g} / \mathrm{ml} \mathrm{BFA}$ for $3 \mathrm{hr}$, while no significant morphological changes were detected in other organelles (Fig. $5 \mathrm{a} \leftarrow$ ). An increase in the number of 
vacuoles has also been observed in BFA-treated $(200 \mu \mathrm{g} / \mathrm{ml})$ maize cells (Satiat-Jeunemaitre and Haws 1992a, b).

The observations in the present study suggest that Golgi cisternae morphologically change by BFA into ER without complete disorganization of the typical Golgi structure. It can be speculated that BFA caused the following events sequentially: 1)disordering the edges of the cisternae, 2)expansion of the cisternae near the edges, 3)extention of the distorted Golgi cisternae, 4)attaching ribosomes to the surface of the cisternae, 5)connection of the ribosomes-attached cisternae with ER.

In tobacco cells BFA inhibited completely the cell wall regeneration(Kaneko and Terasawa 1993) and secretion of one type of the isoforms of APase to be exported by a Golgidependent pathway(to be published elsewhere). These results show that the inhibition of the secretion of the BFA-sensitive APase occurred in the protoplasts by BFA concomitantly with the morphlogical changes of the Golgi cisternae. The inhibition of the secretion of the BFA-sensitive APase may be related to the morphological changes of the Golgi cisternae. Morphological changes without disorganization of the Golgi complex have also been reported in cells of sycamore maple and of rice (Driouich et al., 1993; Kimura et al., 1993). In sycamore maple cells BFA inhibited protein secretion and the incorporation of xylose and fucose into the hemicellulosic polysaccharides of the cell wall (Driouich et al., 1993), while in rice cells the drug inhibited the formation of saccharide moieties of the Golgi membrane glycoproteins (Kimura et al., 1993). These observations suggest that each concentration of BFA used causes some inhibitory effects on the function of Golgi apparatus. BFA at high doses produced vesiculation of the Golgi apparatus in epidermal cells of maize coleoptile segments and maize cells (Satiat-Jeunemaitre and Haws 1992a,b; Schindler et al., 1994).

Although the reasons for these differences are unknown, it seems natural that the sensitivity of the architecture of the Golgi apparatus to BFA varies among plants and/or tissues. It is likely that the investigation on these differences is important to obtain more significant informations to elucidate the structure and function of Golgi apparatus.

In this connection, it is of interest that the Golgi apparatus of mammalian cells of epithelial origin is morphologically insensitive to BFA : in maidon-darby canine kidney cells BFA preferentially inhibited protein secretion from the apical cell surface (Low et al., 1991). Furthermore the preferential inhibition of apical secretion was achieved by a BFA concenration that essentially did not affect total protein secretion nor the Golgi structure. In many mammalian cells BFA does however induce a redistribution of proteins that are present in the Golgi to the ER, with concomitant disorganization of the structure of the Golgi apparatus (Klausner et al., 1992).

\section{Acknowledgement}

We wish to thank Dr. K. Takabe, Kyoto University, Kyoto, for his helpful discussions.

\section{References}

Akert, K., and C.Sandri. 1975. Significance of the maillet method for cytochemical studies of synapses. In Santini,M.(ed.): Golgi Centennial Symposium. Proceedings pp.387399. Raven Press, New York.

Arioka,M., A.Hirata, A.Takatsuki and M.Yamasaki. 1991. Brefeldin A blocks an early stage of protein transport in Candida albicans. J. Gen. Microbiology 137:1253-1262. 
Doms, R.W., G.Russ and J.W.Yewdell. 1989. Brefeldin A redistributes resident and itinerant Golgi proteins to the endoplasmic reticulum. J. Cell Biology 109:51-72.

Draget, K.I., S.Myhre and K.Ostgaard. 1988. Plant protoplast immobilized in calcium alginate. A simple method of preparing fragile cells for transmission electron microscopy. Stain Technology 63:159-163.

Driouich, A., G.F.Zhang and L.A.Staehelin. 1993. Effect of brefeldin A on the structure of the Golgi apparatus and on the synthesis and secretion of proteins and polysacchrides in sycamore maple Acer pseudoplatanus suspension culture. Plant Physiol. 101:13631373.

Fujiwara, T., K.Oda, S.Yokota, A.Takatsuki and Y.Ikehara. 1988. Brefeldin A causes disassembly of the Golgi and accumulation of secretory proteins in the endoplasmic reticulum. J. Biol. Chem. 263:18545-18552.

Graham, T.R., P.A.Scott and S.D.Emr. 1993. Brefeldin A reversibly blocks early but not late transport steps in the yeast secretory pathways. EMBO Journal 12:869-877.

Hayashi, T., A.Takatsuki and G.Tamura. 1974. The action mechanism of Brefeldin A. I. Growth recovery of Candida albicans by lipids from the action of Brefeldin A. J. Antibiotics 27:65-72.

Kaneko, T.S. and N.Terasawa. 1993. Inhibitory effect of brefeldin A on cell wall generation of tobacco protoplast. J. Japan Women's Univ. Fac. Sci. 1:59-62.

Kato, S., S.Ito, T.Noguti and H.Naito. 1989. Effects of brefeldin A on the synthesis and secretion of egg white proteins in primary cultured oviduct cells of laying Japanese quail Coturnix coturnix japonica. Biochim. Biophys. Acta. 991:36-43.

Kimura, S., M.Yamada, I.Igaue and T.Mitsui. 1993. Structure and function of the Golgi complex in rice cells: Characterization of Golgi membrane glycoproteins. Plant \& Cell Physiol. 34:855-863.

Klausner, R.D., J.G.Donaldson and J.Lippincott-Schwartz. 1992. Brefeldin A: Insights into the control of membrane traffic and organelle structure. J. Cell. Biol. 116:10711080 .

Low, S.H., S.H.Wong, B.L.Tang, P.Tang, V.N.Subramaniam and W.Hong. 1991. Inhibition by brefeldin A of protein secretion from the apical cell surface of madin-darby canine kidney cells. J. Biol. Chem. 266:17729-17732.

Lippincott-Schwartz, J., L.C.Yuan, J.S.Bonifacino and R.D.Klausner. 1989.

Rapid distribution of Golgi proteins into the ER in cells treated with brefeldin A: Evidence for membrane cycling from the Golgi to the ER. Cell 56:801-813.

Lippincott-Schwartz, J., J.D.Donaldson, A.Schweizer, E.G.Berger, H.P.Hauri, L.C.Yuan and R.Klausner. 1990. Microtubules dependent on retrograde transport of proteins into the ER in the presence of brefeldin A suggests an ER recycling pathway. Cell 60:821-836.

Misumi, Y., Y.Misumi, K.Miki, A.Takatuki, G.Tamura and Y.Ikehara. 1986. Novel blockade by brefeldin A of intracellular transport of secretory proteins in cultured hepatocytes. J. Biol. Chem. 261:11398-11403.

Nagata, T. and I.Takebe. 1970. Cell wall regeneration and cell division in isolated tobacco mesophyll protoplasts. Planta 92:301-308. 
Oda, K., S.Hirose, N.Takami, Y.Misumi, A.Takatsuki and Y.Ikehara. 1987. Brefeldin A arrests the intracellular transport of a precursor of complement C3 before its conversion site in rat hepatocytes. FEBS Lett. 214:135-138.

Satiat-Jeunemaitre, B. and C.Haws. 1992a. Reversible dissociation of the plant Golgi apparatus by brefeldin A. Biol. Cell 74:325-328.

Satiat-Jeunemaitre, B. and C.Haws. 1992b. Redistribution of Golgi glycoprotein in plant cells treated with brefeldin A. J. Cell Science 103:1153-1166.

Schindler, T., R.Bergfeld, M.Hohl and P.Schopfer. 1994. Inhibition of Golgi apparatus function by brefeldin $\mathrm{A}$ in maize coleoptiles and its consequences on auxin-mediated growth, cell-wall extensibility and secretion of cell-wall protein. Planta 192:404-413.

Takatuki, A. and G.Tamura. 1985. Brefeldin A, a specific inhibitor of intracellular translocation of vesicular stomatitis virus $G$ protein:Intracellular accumulation of highmannnose type $\mathrm{G}$ protein and inhibition of its cell surface expression. Agric. Biol. Chem. 49:899-902.

Tamura, G., K.Ando, S.Suzuki, A.Takatsuki, and K.Arima. 1968. Antiviral activity of Brefeldin A and Verrucarin A. J. Antibiotics 21:160-161.

Yamaoka, T., S.Sato, and T.Hayashi. 1969. Secretion of enzymes by plant cells cultured in vitro. J. Fac. Sci. Univ. Tokyo, Sec.3, 10:117-127.

Fig. 1. Part of a fresh protoplast.

a. The Golgi cisternae are parallel with each other.

b. Higher magnification of Golgi apparatus indicated by $G_{1}$ and $G_{2}$ in Fig. 1a.

The Golgi stack consists of 4 to 6 flattened cisternae.

$\mathrm{a}, \times 24,000 ; \mathrm{b}, \times 50,000$.

Fig. 2. Part of a control protoplast after $3 \mathrm{hr}$ in protoplast medium.

The Golgi stack is consisted of 5 flattened cisternae which were parallel with each other. $\times 15,000$.

Fig.3. Part of a protoplast treated with $10 \mu \mathrm{g} / \mathrm{ml}$ BFA for $1 \mathrm{hr}$.

a. Abnormal Golgi apparatus indicated by $\mathrm{G}_{1}, \mathrm{G}_{2}$ and $\mathrm{G}_{3}$ are shown.

b, c. Higher magnification of the Golgi apparatus in Fig. 3a.

The edges of the cisternae are disordered.

c. A part of these cisternae has expanded $(\leftarrow)$.

b, c. A few ribosomes $(<)$

are attached to the surface of the extended cisternae.

$\mathrm{a}, \times 18,000 ; \mathrm{b}, \times 50,000 ; \mathrm{c}, \times 50,000$.

Fig.4. Part of a protoplast treated with $10 \mu \mathrm{g} / \mathrm{ml} \mathrm{BFA}$ for $2 \mathrm{hr}$ in protoplast medium.

a. $\quad$ The extended cisternae $(\leftarrow)$ are apparent.

b. Higher magnification of Fig. 4a.

The extended cisternae and numerous ribosomes $(<)$ attached to the cisternae can be seen. 


$$
\mathrm{a}, \times 18,000 ; \mathrm{b}, \times 30,000 \text {. }
$$

Fig. 5. Part of a protoplast treated with $10 \mu \mathrm{g} / \mathrm{ml} \mathrm{BFA}$ for $3 \mathrm{hr}$ in protoplast medium.

a, b. Expanded and extended Golgi cisternae are visible.

a. Many vacuoles $(\leftarrow)$ are visible in the cytoplasm.

b. Ribosomes $(<)$ of the tips of the cisternae. a, $\times 18,000 ; b, \times 40,000$.

\section{Key to abbreviations}

Al, alginate bead; CM, cell membrane; ER, endoplasmic reticulum; G, Golgi appratus; M, mitochondrion; P, proplastid; V, vacuole; Bars indicate $0.5 \mu \mathrm{m}$. 

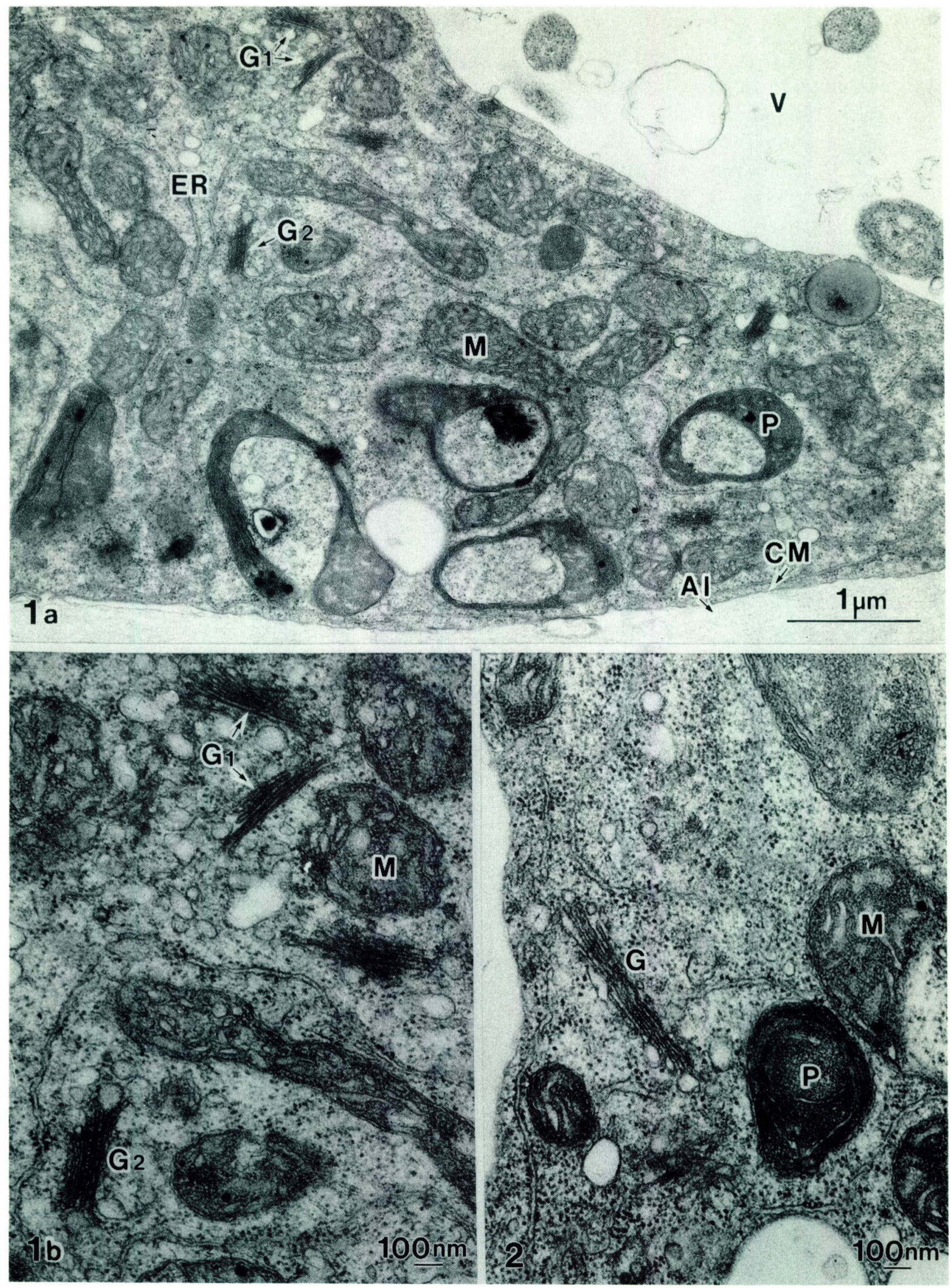


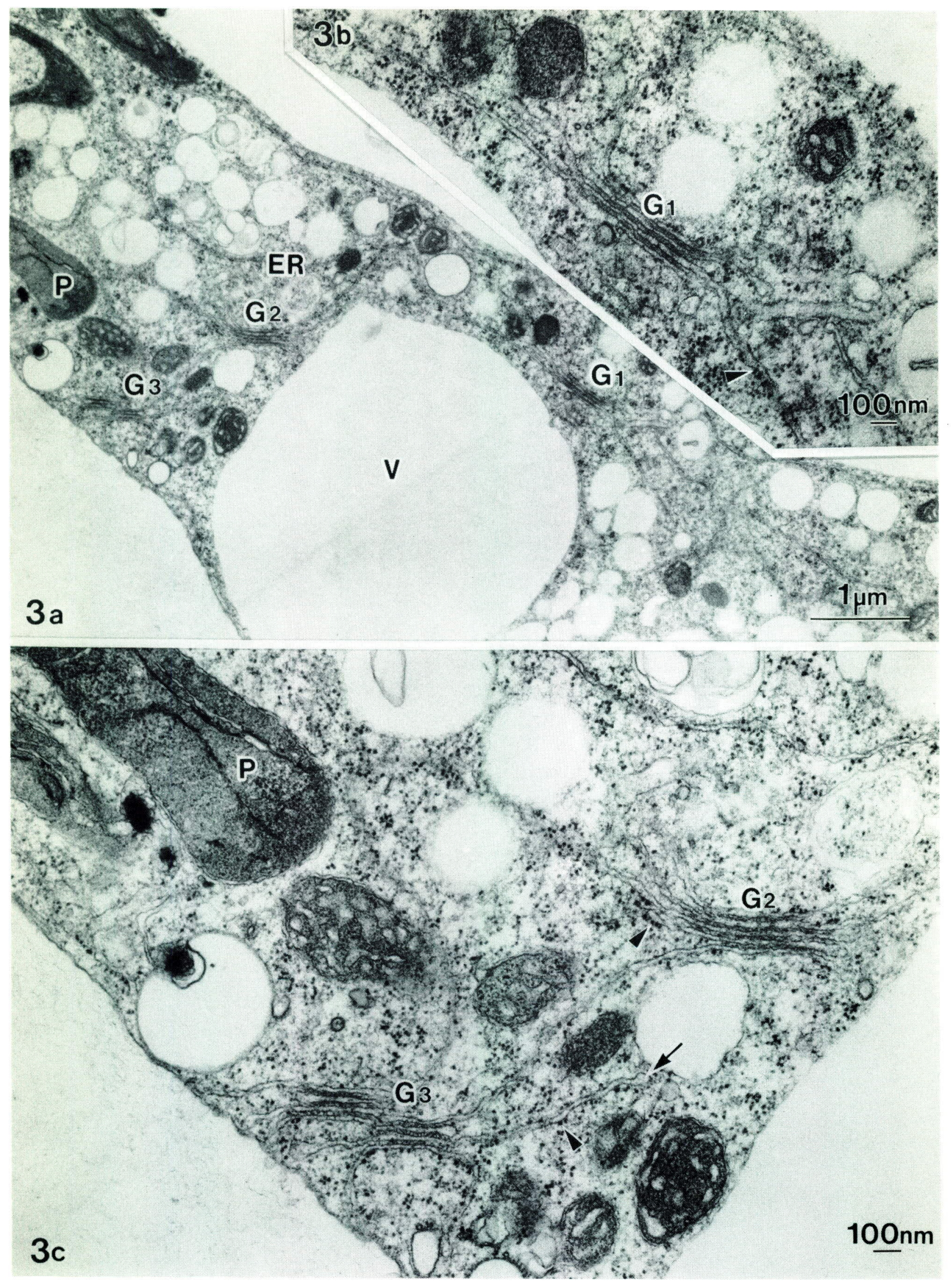




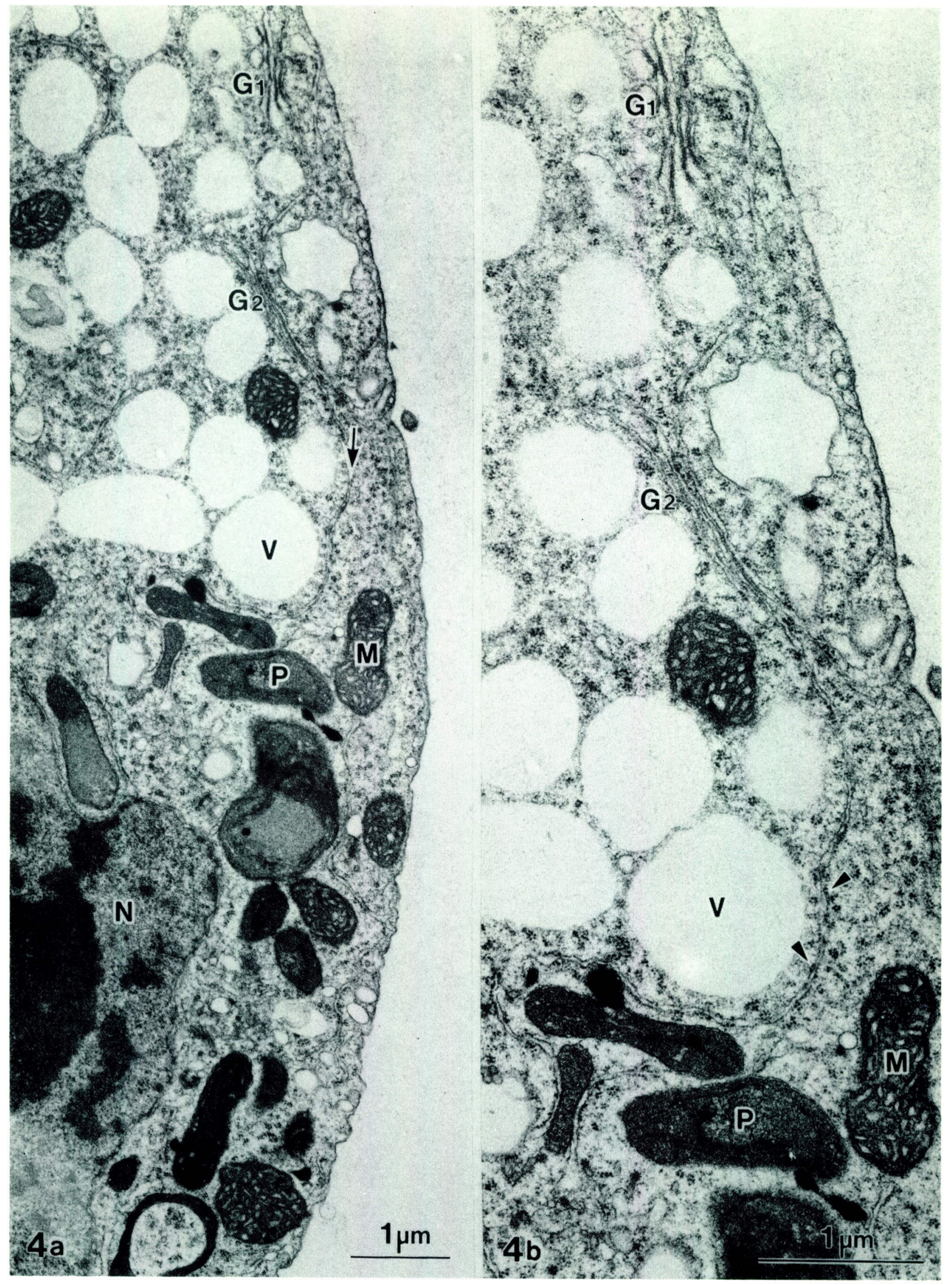



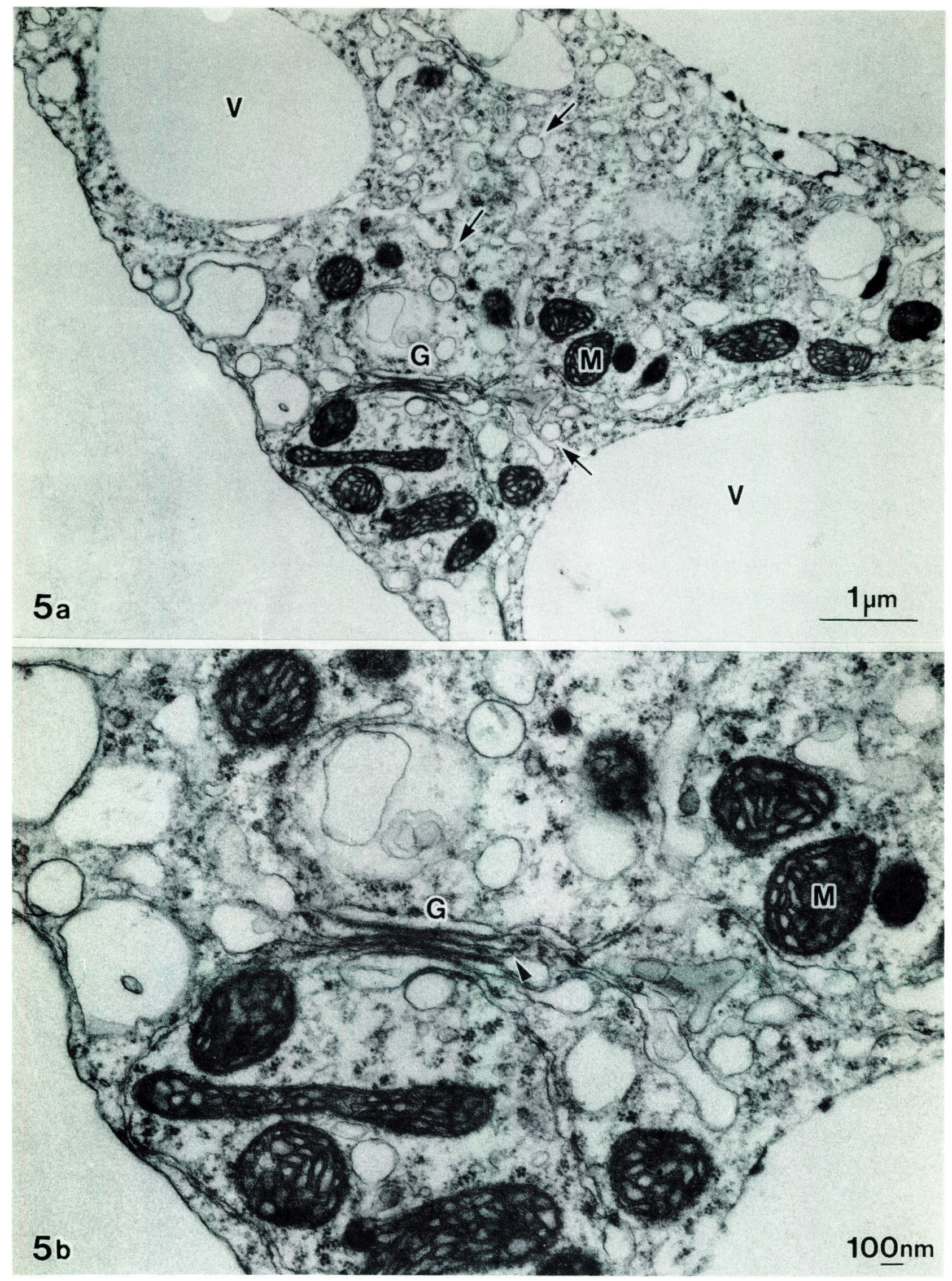